\title{
A Note on Bipartite Graphs with Domination Number 2 and 3
}

\author{
Havva Kirgiz ${ }^{*}$, A. Dilek Maden ${ }^{2}$ \\ ${ }^{1 *}$ Selçuk University, Faculty of Science, Department of Mathematics, Konya, Turkey, (ORCID: 0000-0003-0985-024X), kirgizhavva@gmail.com \\ ${ }^{2}$ Selçuk University, Faculty of Science, Department of Mathematics, Konya, Turkey, (ORCID: 0000-0001-7717-0241), aysedilekmaden@selcuk.edu.tr
}

(1st International Conference on Applied Engineering and Natural Sciences ICAENS 2021, November 1-3, 2021)

(DOI: 10.31590/ejosat.1012651)

ATIF/REFERENCE: Kirgiz, H. \& Maden, A.D. (2021). A Note on Bipartite Graphs with Domination Number 2 and 3. European Journal of Science and Technology, (28), 1071-1076.

\begin{abstract}
When each edge of a connected $G$ graph is replaced by a unit resistor, the resistance distance is computed as the effective resistance between any two vertices in $G$. The Kirchhoff index of $G$ is given by the sum of resistance distances between all pairs of vertices. The multiplicative eccentricity resistance-distance (MERD) of a connected graph $G$ is defined as $\xi_{R}^{*}(G)=\sum_{\left\{v_{i}, v_{j}\right\} \subseteq V_{G}} \varepsilon_{G}\left(v_{i}\right) \varepsilon_{G}\left(v_{j}\right) r_{G}\left(v_{i}, v_{j}\right)$, where $V_{G}$ is the set of vertices of $G, r_{G}\left(v_{i}, v_{j}\right)$ is the resistance-distance between the vertices $v_{i}$ and $v_{j}, \varepsilon_{G}\left(v_{i}\right)$ and $\varepsilon_{G}\left(v_{j}\right)$ are the eccentricity of the vertices $v_{i}$ and $v_{j}$, respectively. The $M E R D$ of the $G$ can be obtained by using Kirchhoff index. In this paper, we characterize the bipartite graphs which have the smallest and largest $M E R D$ with domination number 2 are given. We also characterize the bipartite graphs which have the smallest $M E R D$ with the domination number 3 .
\end{abstract}

Keywords: Electric circuits, Kirchhoff index, Bipartite graphs, Resistance-distance.

\section{Baskınlık Sayısı 2 ve 3 Olan İki Parçalı Graflar Üzerine Bir Not}

Öz

Bağlantılı bir $G$ grafının tüm kenarları birim direnç ile değiştirildiğinde, direnç mesafesi $G$ 'nin herhangi iki köşesi arasındaki efektif direnç olarak hesaplanır. $G$ 'nin Kirchhoff indeksi tüm köşe çiftlerinin direnç mesafelerinin toplamı olarak tanımlanır. $V_{G}$, $G$ 'nin köşelerinin kümesi, $r_{G}\left(v_{i}, v_{j}\right)$ ise $v_{i}$ ile $v_{j}$ köşeleri arasındaki direnç mesafesi ve $\varepsilon_{G}\left(v_{i}\right), \varepsilon_{G}\left(v_{j}\right)$ de sırasıyla $v_{i}$ ve $v_{j}$ köşelerinin eksantriği olmak üzere, bağlantılı bir $G$ grafının çarpımsal eksantrik direnç mesafası $(C ̧ E D M) \xi_{R}^{*}(G)=\sum_{\left\{v_{i}, v_{j}\right\} \subseteq V_{G}} \varepsilon_{G}\left(v_{i}\right) \varepsilon_{G}\left(v_{j}\right) r_{G}\left(v_{i}, v_{j}\right)$ olarak tanımlanır. $G$ grafının ÇEDM’i Kirchhoff indeksini kullanarak hesaplanabilir. Bu makalede, baskınlık sayısı 2 olan iki parçalı graflardan en küçük ve en büyük ÇEDM'e sahip olanlar karakterize edilmiştir. Ayrıca baskınlık sayısı 3 olan iki parçalı graflardan en küçük ÇEDM'e sahip olanlar karakterize edilmiştir.

Anahtar Kelimeler: Elektik devreleri, Kirchhoff indeks, İki parçalı graflar, Direnç mesafesi.

\footnotetext{
${ }^{*}$ Corresponding Author: kirgizhavva@gmail.com
} 


\section{Introduction}

All graphs are considered connected, simple and finite in this study. Let $G=\left(V_{G}, E_{G}\right)$ be a graph where $V_{G}=\left\{v_{1}, v_{2}, \ldots, v_{n}\right\}$ denotes the vertex set of $G$ and $E_{G}$ denotes its edge set. The distance between any two vertices $v_{i}$ and $v_{j}$ in $G$ is denoted by $d_{G}\left(v_{i}, v_{j}\right)$ is the length of shortest path between $v_{i}$ and $v_{j}$. The eccentricity of a vertex $v_{i}$ is denoted by $\varepsilon_{G}\left(v_{i}\right)$ is the maximum distance between $v_{i}$ and a vertex in $V_{G}$. The diameter $D$ of $G$ is $\max \left\{\varepsilon_{G}\left(v_{i}\right): u \in V_{G}\right\}$. The resistance distan-ce is denoted by $r_{G}\left(v_{i}, v_{j}\right)$ which is defined as the effective resistance between any two vertices $v_{i}$ and $v_{j}$, in $G$ when all edges of $G$ is replaced by a resistor of $1 \mathrm{Ohm}$. Let a battery be connected between vertices $v_{i}$ and $v_{j}$; and let $I>0$ be the net current. The effective resistance $r_{G}\left(v_{i}, v_{j}\right)$ between vertices $v_{i}$ and $v_{j}$ is defined by

$$
r_{G}\left(v_{i}, v_{j}\right)=\frac{v_{i}-v_{j}}{I} .
$$

Suppose that $G$ is a connected weighted graph and $w_{i j}$ is the weight of the edge between $v_{i}$ and $v_{j}$ vertices. The resistance distance is defined as

$$
r_{G}\left(v_{i}, v_{j}\right)=\frac{1}{w_{i j}}
$$

when $G$ is edge weighted. Firstly, Klein and Randic [11] introduced the resistance distance, resistance distance matrix and Kirchhoff index $[3,11]$ on the basis of electrical network theory.

The $\operatorname{MERD} \xi_{r}^{*}(G)$ of a graph $G$ is

$$
\xi_{r}^{*}(G)=\sum_{v_{i}, v_{j} \in V_{G}}\left(\varepsilon_{G}\left(v_{i}\right) \varepsilon_{G}\left(v_{j}\right) r_{G}\left(v_{i}, v_{j}\right)\right)
$$

where $\varepsilon_{G}\left(v_{i}\right)$ and $\varepsilon_{G}\left(v_{j}\right)$ are the eccentricity of the related vertices [8].

The minimum cardinality set $S \subseteq V_{G}$ of vertices is called the domination number of graph $G$ when every vertex in $V_{G}-S$ is adjacent to a vertex in $S$. Domination number can be denote by $\gamma(G)=\gamma$. Domination number is well studied in graph theory $[1,2,4,5,6,7,12,14]$.

In this paper, we characterize the bipartite graphs of domination number $\gamma=2$ and $\gamma=3$ which have the smallest and largest MERD.

\section{Material and Method}

We give some theoretical background related to bipartite graphs and the notion of domination number.

The graph $B_{\gamma}\left(n_{1}, n_{2}, \ldots, n_{2 \gamma-1}\right)$ with order $N=\sum_{i=1}^{2 \gamma-1} n_{i}$ is defined by changing the $i$ th vertex on the path $P_{2 \gamma-1}$ by independent sets $V_{i}$ of $n_{i}$ vertices. If any two vertices in the path $P_{2 \gamma-1}$ are adjacent, these two vertices are also adjacent when they are in distinct sets. The graph $B_{\gamma}\left(n_{1}, n_{2}, \ldots, n_{2 \gamma}\right)$ with order $N=\sum_{i=1}^{2 \gamma} n_{i}$ is defined by changing the $i$ th vertex on the path $P_{2 \gamma}$ by independent sets $V_{i}$ of $n_{i}$ vertices. If any two vertices in the path $P_{2 \gamma}$ are adjacent, these two vertices are also adjacent when they are in distinct sets. We should note that $B_{\gamma}\left(n_{1}, n_{2}, \ldots, n_{2 \gamma-1}\right)$ and $B_{\gamma}\left(n_{1}, n_{2}, \ldots, n_{2 \gamma}\right)$ are bipartite graphs with the same domination number $\gamma$.

In the following, we give some useful lemmas for the proof of our main results.

\section{Lemma 2.1 .}

Let $G^{+}=G+e$ where $e$ is a new edge between any two distinct vertices of $G$. Then $\xi_{r}^{*}(G)>\xi_{r}^{*}\left(G^{+}\right)$[9].

\section{Lemma 2.2.}

Let $G$ be a bipartite graph of diameter $D \geq 3$. Then $G$ is a subgraph of a member in $B_{D}\left(n_{1}=1, n_{2}, \ldots, n_{D}, n_{D+1}=1\right)$ [10].

We obtain the following result by using Lemma 2.2.

\section{Corollary 2.3.}

If $\gamma \geq 2$, all bipartite graphs with domination number $\gamma$ is a subgraph of a member in the class of graphs

or

$$
B_{\gamma}\left(n_{1}=1, n_{2}, n_{3}, \ldots, n_{2 \gamma-1}=1\right)
$$

$$
B_{\gamma}\left(n_{1}=1, n_{2}, n_{3}, \ldots, n_{2 \gamma}=1\right) .
$$

\section{Lemma 2.4 .}

Let $G=B_{D}\left(n_{1}, n_{2}, \ldots, n_{D+1}\right)$ where $D$ is the diameter of graph $G$. The Kirchhoff index $K f(G)$ of the graph $G$ is

$$
K f(G)=\sum_{i=1}^{D+1}\left(\frac{N-\sum_{k=1}^{i-1} n_{k}}{n_{i-1} n_{i}} \sum_{k=1}^{i-1} n_{k}\right)+N \sum_{j=1}^{D+1} \frac{n_{j}-1}{n_{j-1}+n_{j+1}}
$$


where $n_{0}=n_{D+2}=0[10]$.

Using the above lemma, the following corollary can be given.

\section{Corollary 2.5.}

If we use the domination number $\gamma$ of graph $G$ instead of the diameter, then we calculate the Kirchhoff index of $G$ as follows:

$K f(G)=\sum_{i=1}^{q}\left(\frac{N-\sum_{k=1}^{i-1} n_{k}}{n_{i-1} n_{i}} \sum_{k=1}^{i-1} n_{k}\right)+N \sum_{j=1}^{q} \frac{n_{j}-1}{n_{j-1}+n_{j+1}}$

where

$$
q=\left\{\begin{array}{l}
2 \gamma \text { and } n_{0}=n_{2 \gamma+1}=0, \quad \text { if } N=\sum_{i=1}^{2 \gamma} n_{i}, \\
2 \gamma-1 \text { and } n_{0}=n_{2 \gamma}=0, \quad \text { if } N=\sum_{i=1}^{2 \gamma-1} n_{i} .
\end{array}\right.
$$

\section{Results}

In this section we give our main results for $B_{\gamma}\left(n_{1}, n_{2}, \ldots, n_{2 \gamma}\right)$ with order $N=\sum_{i=1}^{2 \gamma} n_{i}$. Similar results can be given for $B_{\gamma}\left(n_{1}, n_{2}, \ldots, n_{2 \gamma-1}\right)$ with order $N=\sum_{i=1}^{2 \gamma-1} n_{i}$.

\section{Theorem 3.1.}

Let $G$ be a bipartite graph with $N(N \geq 6)$ vertices and domination number $\gamma=2$. The graphs

$$
B_{2}(1,\lfloor N / 2\rfloor,\lceil N / 2\rceil, 1)
$$

have the smallest $M E R D$.

Proof. Let $G$ be a bipartite graph with domination number $\gamma=2$ and $N$ vertices. The graph $G$ should be in the class $B_{2}\left(1, n_{2}, n_{3}, 1\right)$. Then by Corollary 2.5 we can calculate $K f\left(B_{2}(1, K, N-K-2,1)\right)$ where $1 \leq K \leq 3$.

The MERD of $B_{2}(1, K, N-K-2,1)$ (see, Fig. 1) is given by

$\xi_{R}^{*}\left(B_{2}(1, K, N-K-2,1)\right)=6 K f\left(B_{2}(1, K, N-K-2,1)\right)$

$+3 r_{G}\left(a_{1}, d_{1}\right)-2\left[\sum_{x_{i} \in V_{2}, y_{j} \in V_{3}} r_{G}\left(x_{i}, y_{j}\right)+\sum_{x_{i}, x_{j} \in V_{2}} r_{G}\left(x_{i}, x_{j}\right)\right]$

$-2 \sum_{y_{i}, y_{j} \in V_{3}} r_{G}\left(y_{i}, y_{j}\right)$.

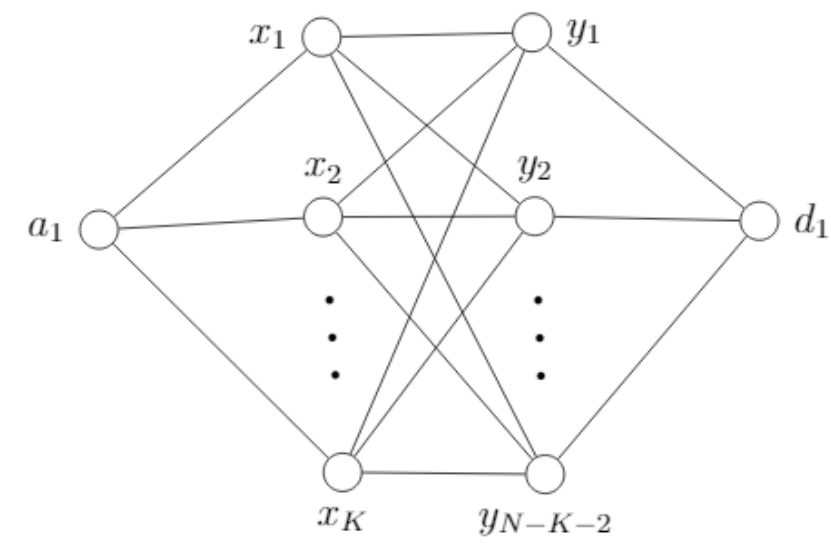

Fig. $1 B_{2}(1, K, N-K-2,1)$.

We calculate $r_{G}\left(a_{1}, d_{1}\right)$ at first. We put a battery between $a_{1}$ and $d_{1}$. The voltages at $x_{1}, x_{2}, \ldots, x_{K}$ and $y_{1}, y_{2}, \ldots, y_{N-K-2}$ are the same. So, we contract them into the vertices $x^{\prime}$ and $y^{\prime}$, respectively. The contracted graph has new resistance distance values on its each edge:

$r_{G}\left(a_{1}, x^{\prime}\right)=1 / K, r_{G}\left(x^{\prime}, y^{\prime}\right)=1 /(K(N-K-2))$,

$r_{G}\left(y^{\prime}, d_{1}\right)=1 /(N-K-2)$.

Then we can easily obtain $r_{G}\left(a_{1}, d_{1}\right)$ :

$$
r_{G}\left(a_{1}, d_{1}\right)=\frac{1-N}{K(K-N+2)}
$$

Now, we should find $\sum_{x_{i} \in V_{2}, y_{j} \in V_{3}} r_{G}\left(x_{i}, y_{j}\right)$ (Fig. 2). In this step, it is enough to find $r_{G}\left(x_{1}, y_{1}\right)$. We delete $r_{G}\left(x_{1}, y_{1}\right)$ edge to obtain $B_{2}^{-}(1, K, N-K-2,1)$. We put a battery between $x_{1}$ and $y_{1}$. The voltages at $x_{2}, x_{3}, \ldots, x_{K}$ and $y_{2}, y_{3}, \ldots, y_{N-K-2}$ are the same. So we contract them into the vertices $x^{\prime}$ and $y^{\prime}$, respectively.

This yields a new contracted graph and the resistance distance of the new graph is given as follows (Fig. 3):

$$
\begin{aligned}
& r_{G}\left(a_{1}, x^{\prime}\right)=r_{G}\left(y_{1}, x^{\prime}\right)=1 /(K-1), \\
& r_{G}\left(a_{1}, x_{1}\right)=r_{G}\left(d_{1}, y_{1}\right)=1, \\
& r_{G}\left(x^{\prime}, y^{\prime}\right)=1 /((K-1)(N-K-3)), \\
& r_{G}\left(d_{1}, y^{\prime}\right)=r_{G}\left(a_{1}, y^{\prime}\right)=1 /(N-K-3) .
\end{aligned}
$$




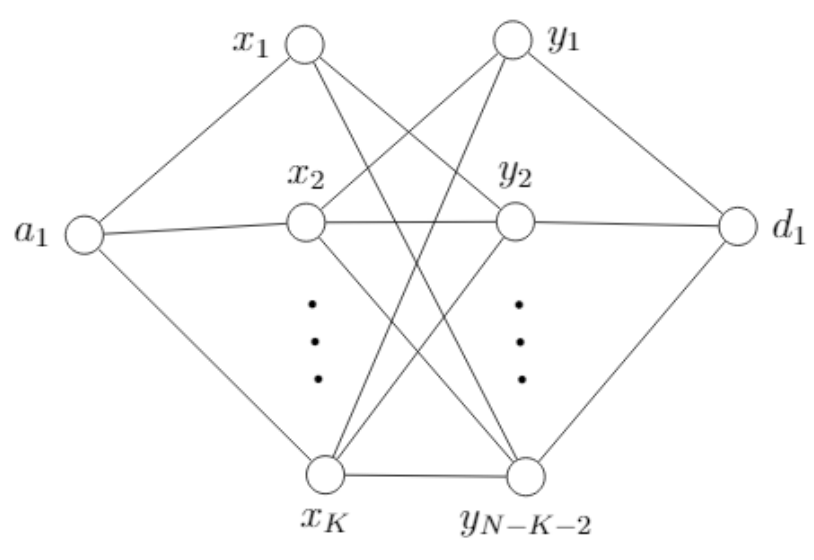

Fig. 2. Graphs used to find $\sum_{x_{i} \in V_{2}, y_{j} \in V_{3}} r_{G}\left(x_{i}, y_{j}\right)$.

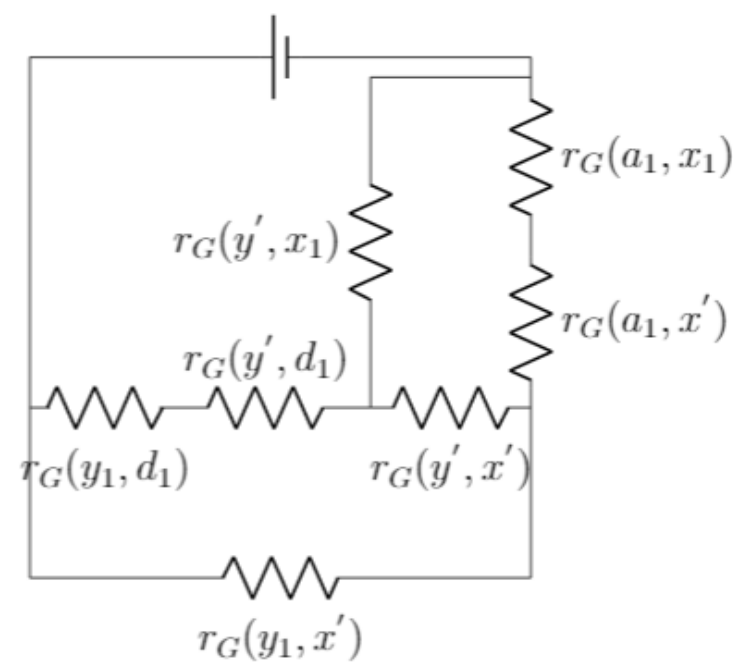

Fig. 3. The circuit diagram of Fig.2.

We compute $r_{G}^{-}\left(x_{1}, y_{1}\right)$ by using $Y-\Delta$ equivalent transformation:

$$
r_{G}^{-}\left(x_{1}, y_{1}\right)=\frac{K^{2}(1-N)+2 K+K N(N-3 K)+1}{\left(K^{2}-K(2+N)+1\right)\left(K^{2}+K(2-N)-1\right)}
$$

and

$$
\sum_{x_{i} \in V_{2}, y_{j} \in V_{3}} r_{G}\left(x_{i}, y_{j}\right)=\frac{K^{2} N-K^{2}-K N^{2}+3 K N-2 K-1}{(K-N+1)(K+1)} .
$$

We calculate $r_{G}\left(x_{1}, x_{2}\right)$ to find $\sum_{x_{i}, x_{j} \in V_{2}} r_{G}\left(x_{i}, x_{j}\right)$. Now, we put a battery between $x_{1}$ and $x_{2}$. Contracting $x_{3}, x_{4}, \ldots, x_{K}$ and $y_{1}, y_{2}, \ldots, y_{N-K-2}$ into the vertices $x^{\prime}$ and $y^{\prime}$, respectively. e-ISSN: 2148-2683
Then we obtain $r_{G}\left(x_{1}, x_{2}\right)$ by using $Y-\Delta$ equivalent transformation:

$$
r_{G}\left(x_{1}, x_{2}\right)=2 /(N-K-1)
$$

and

$$
\sum_{x_{i}, x_{j} \in V_{2}} r_{G}\left(x_{i}, x_{j}\right)=\frac{K(K-1)}{N-K-1} .
$$

Lastly, we compute $\sum_{y_{i}, y_{j} \in V_{3}} r_{G}\left(y_{i}, y_{j}\right)$ by using circuit diagrams.

We use a method similar to the one used to calculate

$\sum_{x_{i}, x_{j} \in V_{2}} r_{G}\left(x_{i}, x_{j}\right)$. Thus we have

$$
\sum_{y_{i}, y_{j} \in V_{3}} r_{G}\left(y_{i}, y_{j}\right)=\frac{(N-K-2)(N-K-3)}{K+1} .
$$

Finally we calculate the $M E R D$ of $B_{2}(1, K, N-K-2,1)$ as follows:

$\xi_{R}^{*}\left(B_{2}(1, K, N-K-2,1)\right)=6 K f\left(B_{2}(1, K, N-K-2,1)\right)$

$+\frac{3(1-N)}{K(K-N+2)}-2\left[\frac{K^{2} N-K^{2}-K N^{2}+3 K N-2 K-1}{(K-N+1)(K+1)}\right]$

$-\frac{2 K(K-1)}{N-K-1}-\frac{2[(N-K-2)(N-K-3)]}{K+1}$.

It can be easily seen that $\xi_{R}^{*}\left(B_{2}(1, K, N-K-2,1)\right)$ reaches its minimum value for $K=(N-2) / 2$. If $N$ is even

$\xi_{R}^{*}\left(B_{2}(1, K, N-K-2,1)\right)$

$=\frac{K^{3}(8 K-28)+N(44 N+60)-128}{N\left(N^{2}-4 N+4\right)}$.

If $N$ is odd we have

$\xi_{R}^{*}\left(B_{2}(1, K, N-K-2,1)\right)=\frac{8 N^{3}-28 N^{2}+52 N}{N^{2}-4 N+3}$.

Theorem 3.2.

Let $G$ be a bipartite graph with $N$ vertices and domination number $\gamma=2$. Then the graphs

$$
B_{2}(\lfloor N / 2\rfloor-1,1,1,\lceil N / 2\rceil-1)
$$

have the largest MERD. 
Proof. Since the bipartite graphs with domination number $\gamma=2$ which have the largest Kirchhoff index are tree, the bipartite graphs which have the largest MERD should be a member in $B_{2}(K, 1,1, N-K-2)(1 \leq K \leq N-3)$. From Corollary 2.5 , we have

$K f\left(B_{2}(K, 1,1, N-K-2)\right)=N^{2}-(K+N)(K+2)+1$.

We take

$T=\left\{t_{1}, t_{2}, \ldots, t_{N-K-2}\right\}, \quad X=\left\{x_{1}, x_{2}, \ldots, x_{K}\right\}, \quad Y=\left\{y_{1}\right\} \quad$ and $Z=\left\{z_{1}\right\}$ where $T, X, Y$ and $Z$ are independent sets of $n_{i}$ vertices.

Hence,

$\xi_{R}^{*}\left(B_{2}(K, 1,1, N-K-2)\right)=6 K f\left(B_{2}(K, 1,1, N-K-2)\right)$

$-2 r_{G}\left(y_{1}, z_{1}\right)+3\left(\sum_{x_{i} \in X, t_{j} \in T} r_{G}\left(x_{i}, t_{j}\right)+\sum_{x_{i}, x_{j} \in X} r_{G}\left(x_{i}, x_{j}\right)\right)$

$+3 \sum_{t_{i}, t_{j} \in T} r_{G}\left(t_{i}, t_{j}\right)$

Clearly,

$r_{G}\left(y_{1}, z_{1}\right)=1, \quad \sum_{t_{i}, t_{j} \in T} r_{G}\left(t_{i}, t_{j}\right)=\frac{2(N-K-2)(N-K-3)}{2}$,

$\sum_{x_{i} \in X, t_{j} \in T} r_{G}\left(x_{i}, t_{j}\right)=3 K(N-K-2)$,

$\sum_{x_{i}, x_{j} \in X} r_{G}\left(x_{i}, x_{j}\right)=\frac{2 K(K-1)}{2}$.

Thus, we have

$$
\begin{aligned}
& \xi_{R}^{*}\left(B_{2}(K, 1,1, N-K-2)\right) \\
& =9 K(N-K)-18 K+9 N(1-3 N)+22 .
\end{aligned}
$$

One can easily see that $\xi_{R}^{*}\left(B_{2}(K, 1,1, N-K-2)\right)$ has the maximum value for $K=\lfloor N / 2\rfloor-1$.

In the following theorem, we consider the almost complete bipartite graphs $G(m, p)=K_{m, m}-p K_{2}$ for convenience. The vertex set of the almost complete bipartite graph is $V=\left\{\alpha_{1}, \alpha_{2}, \ldots, \alpha_{m}\right\} \cup\left\{\beta_{1}, \beta_{2}, \ldots, \beta_{m}\right\}$ and its edge set is $E=\left\{\alpha_{i} \beta_{j} \mid 1 \leq i, j \leq n\right\} \backslash\left\{\alpha_{1} \beta_{1}, \alpha_{2} \beta_{2}, \ldots, \alpha_{p} \beta_{p}\right\}[13]$.

Now, we obtain the bipartite graphs which have the smallest $M E R D$ with domination number $\gamma=3$ and order $N\left(N=4 \alpha, \alpha \in \phi^{+}-\{1\}\right)$.
The graphs

$$
B_{3}\left(1, \frac{N}{4}, \frac{N}{2}-2, \frac{N}{4}, 1\right)
$$

have the smallest MERD in almost complete bipartite graphs of order $N\left(N=4 \alpha, \alpha \in \varnothing^{+}-\{1\}\right)$ with domination number $\gamma=3$.

Proof. Since the bipartite graphs with domination number $\gamma=3$ is a subgraph of

$B_{3}\left(n_{1}=1, n_{2}=M, n_{3}=K, n_{4}=N-M-K-2, n_{5}=1\right)$

where $N=4 \alpha, \alpha \in \phi^{+}-\{1\}$ and $1 \leq M+K \leq N-2$, by Corollary 2.5. we have

$$
\begin{aligned}
& K f\left(B_{3}(1, M, K, N-M-K-2,1)\right) \\
& =\frac{N-1}{M}-\frac{N-1}{K+M-N+2}-N\left(\frac{K-1}{K-N+2}-\frac{M-1}{K+1}\right) \\
& +\frac{(K+M+1)(K+M-N+1)}{K(K+M-N+2)}-\frac{(M+1)(M-N+1)}{K M} \\
& +\frac{N(K+M-N+3)}{K+1} .
\end{aligned}
$$

Let

$$
X=V_{1} \mathrm{U} V_{3} \mathrm{U} V_{5}=\left\{a_{1}, y_{1}, y_{2}, . ., y_{K}, d_{1}\right\}
$$

and

$$
Y=V_{2} \mathrm{U} V_{4}=\left\{x_{1}, x_{2}, \ldots, x_{K}, z_{1}, z_{2}, \ldots, z_{N-M-K-2}\right\}
$$

where $(X, Y)$ is the bipartition of the graph. Since the graph is an almost complete bipartite graph we have $X=Y$.

The eccentricities of vertices $a_{1}$ and $d_{1}$ are $\varepsilon\left(a_{1}\right)=\varepsilon\left(d_{1}\right)=4$. Also, the eccentricities of vertices in $V_{2}$, $V_{4}$ and $V_{3}$ are $\varepsilon\left(V_{2}\right)=\varepsilon\left(V_{4}\right)=3, \varepsilon\left(V_{3}\right)=2$. Thus, the $M E R D$ of $B_{3}(1, M, K, N-M-K-2,1)$ is

$\xi_{R}^{*}\left(B_{3}(1, M, K, N-M-K-2,1)\right)$

$=12 K f\left(B_{3}(1, M, K, N-M-K-2,1)\right)$

$+4 r_{G}\left(a_{1}, d_{1}\right)-6\left[\sum_{x_{i} \in V_{2}, y_{j} \in V_{3}} r_{G}\left(x_{i}, y_{j}\right)+\sum_{y_{i} \in V_{3}, z_{j} \in V_{4}} r_{G}\left(y_{i}, z_{j}\right)\right]$

\section{Theorem 3.3.}




$$
\begin{aligned}
& -8 \sum_{y_{i}, y_{j} \in V_{3}} r_{G}\left(y_{i}, y_{j}\right)-3\left(\sum_{x_{i}, x_{j} \in V_{2}} r_{G}\left(x_{i}, x_{j}\right)+\sum_{z_{i}, z_{j} \in V_{4}} r_{G}\left(z_{i}, z_{j}\right)\right) \\
& -3 \sum_{x_{i} \in V_{2}, z_{j} \in V_{4}} r_{G}\left(x_{i}, z_{j}\right) .
\end{aligned}
$$

Clearly, the graphs

$$
B_{3}\left(1, \frac{N}{4}, \frac{N}{2}-2, \frac{N}{4}, 1\right)
$$

have the smallest MERD in almost complete bipartite graphs of order $N\left(N=4 \alpha, \alpha \in \phi^{+}-\{1\}\right)$ with domination number $\gamma=3$.

\section{Conclusions and Recommendations}

Jiang et al. [10], identified bipartite graphs of diameter 3 with the largest and smallest Kirchhoff index. In this paper, we identify the bipartite graphs with domination number $\gamma=2$ having the smallest, largest and with domination number $\gamma=3$ having the smallest $M E R D$ by using the results in [10]. Our main method consists of basic electric circuit rules. Future works include finding the largest $M E R D$ of the bipartite graphs with domination number $\gamma=3$ and the smallest, largest MERD of the bipartite graphs with domination number $\gamma \geq 4$.

\section{Acknowledge}

This work is based on Havva Kırgız's Ph.D. dissertation.

\section{References}

[1] S. Artmann, and A. Pruchnewski, "Constructing a Dominating Set for bipartite graphs in several Rounds", Techn. Univ., Inst. für Mathematik, 2009.

[2] S. Artmann and J. Harant, "Random procedures for dominating sets in bipartite graphs", Discussiones Mathematicae Graph Theory, vol. 30, pp. 277-288, 2010.

[3] D. Bonchev, A.T. Balaban, X. Liu, D. J. Klein, "Molecular cyclicity and centricityof polycyclic graphs I. Cyclicity based on resistance distances or reciprocal distances", Int. J. Quantum Chem. vol. 50, pp. 1-20, 1994.

[4] T. Gerlach and J. Harant, "A note on domination in bipartite graphs", Discussiones Mathematicae Graph Theory vol. 22, pp.229-231, 2002.

[5] J. Harant and D. Rautenbach. "Domination in bipartite graphs." Discrete mathematics vol. 309, pp. 113-122, 2009.

[6] J. Harant and A. Pruchnewski, "A note on the domination number of a bipartite graph", Annals of Combinatorics vol. 5, pp.175-178, 2001.

[7] M. A. Henning, I. Schiermeyer and A. Yeo, "A new bound on the domination number of graphs with minimum degree two", the electronic journal of combinatorics pp.12-12, 2011.

[8] Y. Hong, Z. Zhu, A. Luo, "Some transformations on multiplicative eccentricity resistance-distance and their applications", Appl. Math. Comput. vol. 323, pp. 75-85, 2018.

[9] Y. Hong, Z. Zhu, A. Luo, "Extremal graphs with diameter 2 for two indices on resistance-distance", Discrete Math. vol. 342, pp. 487-497, 2019.

[10] X. J. Jiang, W. H. He, Q. Liu, J. P. Li, "On the Kirchhoff index of bipartite graphs with given diameters", Discrete Appl. Math. vol. 283, pp. 512-521, 2020.

[11] D. J. Klein, M. Randic, "Resistance distance", J. Math. Chem. vol. 12, pp. 81-95, 1993.

[12] N. J. Rad, "New Probabilistic Upper Bounds on the Domination Number of a Graph", The Electronic Journal of Combinatorics pp.3-28, 2019.

[13] L. Ye, W. Yan, "Resitance between two vertices of almost complete bipartite graphs", Discrete Applied Mathematics, vol. 257, pp. 299-305.

[14] H. M. Xing, L. Sun, X. G. Chen, "An upper bound for domination number of 5-regular graphs", Czechoslovak Mathematical Journal vol. 56, pp. 1049-1061, 2006. 